\title{
Institutional and operator recommendations for percutaneous coronary interventions
}

\section{Christoph Kaisera, \\ Stéphane Cook ${ }^{a}$, \\ Peter Wenaweser ${ }^{\text {, }}$ \\ Michael Zellweger ${ }^{b}$, \\ Giovanni Pedrazzini ${ }^{b}$}

On behalf of the Working Group of Interventional Cardiology and Acute Coronary Syndromes ${ }^{\mathrm{a}}$ and of the Swiss Society of Cardiology
Correspondence:

Prof. Dr. med. Christoph Kaiser, MD, FESC

Department of Cardiology

University Hospital

Petersgraben 4

CH-4031 Basel

christoph.kaiser[at]usb.ch

\section{Introduction}

Over the past 10 years, interventional cardiology has experienced technical developments that have paved the way to interventions not even conceivable one decade ago including, among others, transcatheter aortic valve implantation (TAVI), percutaneous mitral valve repair and left atrial appendage closure. Moreover, percutaneous coronary intervention (PCI) has now been adopted countrywide as the treatment of choice for patients with acute coronary syndrome (ACS).

During the same period of time, in Switzerland the number of interventional centers has increased, while the trend with respect to volume differed from center to center. This evolution has unavoidably led to a higher level of competition among interventional centers.

In order to ensure patient safety and treatment quality in interventional cardiology the board of the Working Group has received the mission by the board of the Swiss Society of Cardiology to provide recommendations for percutaneous coronary interventions in acute and chronic coronary heart disease.

\section{Aim of the document}

The present document addresses general aspects of interventional activity (e.g., radioprotection, data collection, and quality control) and specific recommendations for elective PCI and PCI for ACS. The document is based on current international (ESC, ACC) guidelines [1-4], national recommendations [5-9] and on expert consensus (Board of the Working Group).

\section{General recommendations}

\section{a - Informed consent}

- Written informed consent is mandatory for all elective coronary angiography and PCI. In case of emergency the patient should be orally informed about the risks and benefits of the procedure.

\section{b - Radioprotection}

- For each center a certified person should be designated to be responsible for radioprotection according to the Swiss \& European recommendations in this specific field [10].
- Written internal guidelines for radioprotection should be available for all cardiac percutaneous interventions. The minimal data collection for all cases includes measurement and reporting fluoroscopy time and Dose Area Product (DAP, Gyxcm2) of each intervention.

c - Data collection, quality control and auditing General recommendation

- Set-up of a local database and participation of all centers in the nationwide yearly data collection on interventional procedures and in-hospital mortality with publication of the data on the website of the working group (www.ptca.ch) separately for each center.

- Mandatory assessment and reporting of

- Rates of revascularization procedures (PCI and CABG) following diagnostic coronary angiography.

- Ratio of the number of overall PCI performed to the number of overall patients treated.

- Standardized PCI-related in-hospital mortality data, ST-Elevation myocardial infarction (STEMI)-related mortality, procedure-related versus non- procedure related mortality and mortality in patients after or during cardiopulmonary resuscitation).

- Participation of all centers performing primary PCI in the Swiss infarction registry «AMIS Plus».

\section{Auditing of the facilities by the Working group} in agreement with the SSC according to the present recommendations:

- Mandatory for each new interventional center within the first 6 months of activity.

- Further auditing only by necessity/on special request.

\section{Specific recommendations}

The absolute numbers in the following recommendations apply to single centers and not to PCI-networks or hospital groups.

\section{a - Elective $\mathrm{PCI}$}

Recommendations for operators

- Completed fellowship in interventional cardiology according to the European/Swiss guidelines 
$[11,12]$ with final assessment by the program director.

- Minimal annual number of procedures for individual operators: 50 PCI as first operator.

\section{Recommendations for institutions}

- On-site intensive or intermediate care unit(s) (see below).

- For centers without cardiac surgery on site, a formal collaboration with a tertiary center is mandatory.

- Official accreditation of new catheterization laboratory by the SSC and our Working Group.

- Minimal number of procedures for interventional centers: 200 PCI per year.

\section{b- $\mathrm{PCI}$ for primary $\mathrm{PCI}$ in STEMI or ACS with hemodynamic instability \\ Out-of-hospital recommendations}

- Ambulance teams to identify STEMI (with use of ECG recorders and telemetry as necessary).

- Pre-Hospital management of STEMI patients must be based on regional networks.

\section{Recommendations for operators}

- A minimum of 3 experienced PCI operators with a minimal annual number of 75 PCI cases as first operator.

\section{Recommendations for institutions}

- Primary PCI-centers must deliver a 24/7 service and be able to start primary PCI as soon as possible but preferably within 60 minutes from the initial call.

- On-site intensive care unit.

- A minimal number of 300 elective PCI procedures per year for institutions performing PCI in patients with STEMI or ACS with hemodynamic instability.

\section{Addendum: definition and minimal require- ment for intermediate care unit [13]}

\section{Expertise/availability in}

- Advanced cardiac life support (ACLS)

- Percutaneous temporary pacemaker

- Urgent/emergent Intubation

- Continuous ECG monitoring

- Continuous non-invasive BP monitoring

- Continuous SO2 monitoring

- In the absence of an intensive care unit on-site, the know-how and equipment for few-hours mechanical ventilation must be available

- For centers without intensive care unit on site, formal collaboration with a tertiary center established for immediate patient transfer in case of intensive care requirement is mandatory.

\section{Literature}

1 Task Force on Myocardial Revascularization of the European Society of Cardiology (ESC) and the European Association for Cardio-Thoracic Surgery (EACTS); European Association for Percutaneous Cardiovascular Interventions (EAPCI), Wijn W, Kolh P, Danchin N, Di Mario C, Falk V, Folliguet T, et al. Guidelines on myocardial revascularization. Eur Heart J 2010;20:2501-55

2 Steg PG, James SK, Atar D, Badano LP, Lundqvist CB, Borger MA, et al. Guidelines for the management of acute myocardial infarction in patients presenting with ST-segment elevation: The Task Force on the management of ST-segment elevation acute myocardial infarction of the European Society of Cardiology (ESC). Eur Heart J. 2012;20:2569-619.

3 Levine GN, Bates ER, Blankenship JC, Bailey SR, Bittl JA, Cercek B, et al. 2011 ACCF/AHA/SCAI Guideline for Percutaneous Coronary Intervention: A Report of the American College of Cardiology Foundation/American Heart Association Task Force on Practice Guidelines and the Society for Cardiovascular Angiography and Interventions. JACC. 2011;58:e44-12

4 Harold JG, Bass TA, Bashore TM, Brindis RG, Brush JE Jr, Burke JA, et al. ACCF/AHA/SCAI 2013 update of the clinical competence statement on coronary artery interventional procedures: a report of the American College of Cardiology Foundation/American Heart Association/American College of Physicians Task Force on Clinical Competence and Training (Writing Committee to Revise the 2007 Clinical Competence Statement on Cardiac Interventional Procedures). J Am Coll Cardiol. 2013;62:357-96.

5 Dawkins KD, Gershlick T, de Belder M, Chauhan A, Venn G, Schofield P, et al. Joint Working Group on Percutaneous Coronary Intervention of the British Cardiovascular Intervention Society and the British Cardiac Society. Percutaneous coronary intervention: recommendations for good practice and training. Heart. 2005;91 Suppl 6:vi1-27.

6 Aengevaeren WRM, Laarman GJ, Suttorp MJ, ten Berg JM, van Boven AJ, de Boer MJ et al. Dutch guidelines for interventional cardiology: institutional and operator competence and requirements for training. Neth Heart J. 2005; 13: 416-22.

7 Hamm CW, Bösenberg H, Brennecke R, Daschner F, Dziekan G, Erbel R, et al. German Society of Cardiology-Heart and Cardiovascular Research. [Guidelines for equipping and managing heart catheter rooms (1st revision). Issued by the governing body of the German Society of Cardiology-Heart and Cardiovascular Research. Revised by order of the Committee of Clinical Cardiology. Z Kardiol. 2001;367-76.

8 Hamm CW, Albrecht A, Bonzel T, Kelm M, Lange H, Schächinger V, et al. Diagnostic heart catheterization. Clin Res Cardiol. 2008;97:475-511.

9 Bonzel T, Erbel R, Hamm CW, Levenson B, Neumann FJ Rupprecht HJ, et al. Percutaneous coronary interventions (PCI). Clin Res Cardiol. 2008;97:513-47.

10 Locca D, Bell MR, Verdun FR, Stauffer JC. Radiation safety during percutaneous coronary procedures: how to reduce radiation exposure and it's complications. EuroIntervention. 2008;4:181-92.

11 Di Mario C, Di Sciascio G, Dubois-Randé JL, Michels R, Mills P. Curriculum and syllabus for Interventional Cardiology subspecialty training in Europe. EuroIntervention. 2006 May;2(1):31-6.

12 Cook S, Pedrazzini G, Locca D, Moschovitis A, Goy JJ, Maier $\mathrm{W}$, et al. Fellowship in Interventional Cardiology in Switzerland. Cadiovascular Medicine. 2013;16(3):97-100.

13 Schweizerische Richtlinien für die Anerkennung von Intermediate-Care Units (IMCU) (www.sgi-ssmi.ch/)

These recommendations will be updated periodically according current guidelines. 